\title{
El enemigo de mi enemigo es... Un virus que ataca a las bacterias: los bacteriófagos
}

\author{
María Anel Fuentes Valencia, Adriana Carolina Gil Correa, Carlos \\ Antonio Martínez Palacios, Víctor Manuel Baizabal Aguirre y \\ Juan José Valdez Alarcón
}

\begin{abstract}
Resumen
Los virus son partículas que infectan a todas las formas de vida. Los virus bacteriófagos, que infectan bacterias, fueron descubiertos antes que los antibióticos. A pesar de su tamaño pequeño, han contribuido al desarrollo científico desde hace décadas, como en el descubrimiento de numerosas enzimas con aplicaciones en la biología molecular¹. En este trabajo se analizarán aspectos generales de la biología de los virus bacteriófagos, su contribución a la salud y se presentarán algunos casos exitosos de la terapia antimicrobiana usando bacteriófagos en humanos y animales. Aunque la terapia con bacteriófagos no cuenta con autorización para su uso global, ya existen formulaciones comerciales de bacteriófagos para la industria alimentaria. Se describirá el arma principal de los bacteriófagos, la endolisina, enzima que "revienta" a las bacterias. Las endolisinas se consideran una alternativa más segura que los bacteriófagos, al carecer de material genético. Los bacteriófagos y las endolisinas tienen aplicaciones revolucionarias en la medicina, como vehículos de transporte de moléculas y generación de vacunas, de fantasmas bacterianos, o en la detección diagnóstica de bacterias patógenas.
\end{abstract}

Palabras clave: terapia de bacteriófagos, endolisinas, enzibióticos, partículas tipo virus(vLP), fantasmas bacterianos.

\section{THE ENEMY OF MY ENEMY IS... A VIRUS THAT ATTACKS BACTERIA: BACTERIOPHAGES}

1 Biología molecular: disciplina científica que estudia las funciones de la célula a partir de las moléculas que la componen.

\begin{abstract}
Virus particles infect all life forms. Bacteriophage viruses, the ones that infect bacteria, were discovered before antibiotics. Despite its small size, they have contributed to scientific development such as the discovery of many enzymes with applications in molecular biology. In this paper we describe general aspects of their biology and their contribution to health, along with successful cases of antimicrobial therapy using bacteriophages in humans and animals. Despite the fact that there are no commercial authorizations for its global use, there are commercial bacteriophage formulations for the food industry. We will describe the main weapon of bacteriophages, endolysin, an enzyme useful for lysing bacteria. Endolysins are considered safer than bacteriophages because they lack genetic material. Bacteriophages and endolysins have revolutionary applications in medicine, such as the viral-like particles, useful for small molecules delivery or vaccine design, in the generation of bacterial ghosts and in the diagnostic and detection of pathogenic bacteria.
\end{abstract}

Keywords: phage therapy, endolysin, viral like particles (vLP), bacterial ghosts.

Recepción: 27/09/2020. Aprobación: 10/03/2021.

Dol: http://doi.org/10.22201/cuaieed.16076079e.2021.22.4.1

Universidad Nacional Autónoma de México, Coordinación de Universidad Abierta, Innovación Educativa y Educación a Distancia (CUAIEED) Este es un artículo de acceso abierto bajo la licencia de Creative Commons 4.0 cc)(1)(2) 
"El enemigo de mi enemigo es... Un virus que ataca a las bacterias: los bacteriófagos" María Anel Fuentes Valencia, Adriana Carolina Gil Correa, Carlos Antonio Martínez Palacios, Víctor Manuel Baizabal Aguirre y Juan José Valdez Alarcón Vol. 22, Núm. 4, julio-agosto 2021 Revista Digital Universitaria

María Anel Fuentes Valencia anel921@hotmail.com

Actualmente está inscrita en el Programa Institucional de Doctorado en Ciencias Biológicas de la Universidad Michoacana de San Nicolás de Hidalgo, institución en la cual también realizó sus estudios de Maestría en Ciencias Biológicas y de Licenciatura en Biología. Ha participado en distintos proyectos de investigación con vinculación al sector productivo acuícola del país y con instituciones nacionales e internacionales. Tiene experiencia de 8 años en el diagnóstico de enfermedades en los organismos acuáticos. Su principal área de interés en la investigación es el diagnóstico y desarrollo de estrategias alternativas para el tratamiento de enfermedades infecciosas en los organismos acuáticos.

\section{Adriana Carolina Gil Correa}

qfbgil@hotmail.com

Recién egresada del Programa de Maestría Institucional en Ciencias Biológicas de la Universidad Michoacana de San Nicolás de Hidalgo, institución en la que también realizó sus estudios de licenciatura en Químico-Farmacobiología. Ha participado en diferentes congresos de investigación científica. Cuenta con 8 años de experiencia en microbiología clínica. Su interés actual está en el estudio de los bacteriófagos, sus endolisinas y el desarrollo de estrategias biotecnológicas para el control de las enfermedades infecciosas bacterianas.

\section{Carlos Antonio Martínez Palacios}

cpalacios@umich.mx orcid.org/0000-0003-0703-4599

Profesor investigador de tiempo completo en el Instituto de Investigaciones Agropecuarias y Forestales, responsable técnico del Laboratorio Nacional de Microbiómica y Nutrigenómica Digestiva Animal (lanmda.mx), conacrt/umsnh. Phylosophy Doctor por la Universidad de Stirling, Escocia, Reino Unido; Master in Science por la Universidad de Stirling en acuicultura y pesquerías, con especialidad en nutrición de organismos acuáticos; Maestro en Ciencias por la UNAM en Biología Marina y Limnología. Biólogo por la Facultad de Ciencias de la unAm. Desarrolla Investigación sobre especies de peces nativas y exóticas en nutrigenómica, microbiómica y nutrición. Es miembro del Sistema Nacional de Investigadores, nivel II, cuenta con perfil promep, líder del Cuerpo académico consolidado en Biotecnología Acuícola y Acuicultura uMSNH-CA-142.

Víctor Manuel Baizabal Aguirre

baizabal@umich.mx orcid.org/0000-0001-6816-0404

Profesor e Investigador de tiempo completo en el Centro Multidisciplinario de Estudios en Biotecnología de la Facultad de Medicina Veterinaria y Zootecnia, Universidad Michoacana de San Nicolás de Hidalgo. Se graduó de Doctor en Ciencias en Biotecnología de Plantas en el Centro de Investigación y de Estudios Avanzados del IPN (unidad Irapuato). Durante sus estudios de doctorado se dedicó a estudiar las vías de transducción de señales mediadas por proteína cinasas dependientes de calcio, desde una perspectiva bioquímica. Realizó una estancia posdoctoral como Pew Latin American Fellow in Biomedical Sciences en el Department of Biology and Molecular Genetics de la Universidad de California, San Diego, La Jolla, USA, donde se dedicó al estudio de la regulación de los canales de K+ regulados por voltaje. Fue Profesor visitante durante un año en el Michael Smith Laboratory de la Universidad de British Columbia, Vancouver, Canadá, donde desarrolló un proyecto de investigación sobre las respuestas moleculares que se activan en células endoteliales durante la infección por bacterias patógenas. Sus proyectos de investigación se centran en el descubrimiento, diseño y optimización de compuestos orgánicos de bajo peso molecular que se unan con alta afinidad y modifiquen la actividad de proteínas/enzimas que intervienen en procesos inflamatorios. Para lograr lo anterior, su laboratorio desarrolla modelado molecular por computadora, combinado con técnicas bioquímicas. Actualmente es Investigador Nacional sNI nivel ॥ y tiene nombramiento de perfil deseable prodep. Integrante del Cuerpo Académico Consolidado Microbiología Celular y Genética Molecular umSNH-CA-188. 
"El enemigo de mi enemigo es... Un virus que ataca a las bacterias: los bacteriófagos" María Anel Fuentes Valencia, Adriana Carolina Gil Correa, Carlos Antonio Martínez Palacios, Víctor Manuel Baizabal Aguirre y Juan José Valdez Alarcón

Vol. 22, Núm. 4, julio-agosto 2021 Revista Digital Universitaria

Juan José Valdez Alarcón jose.alarcon@umich.mx orcid.org/0000-0002-0378-5021

Profesor Investigador titular de tiempo completo en el Centro Multidisciplinario de Estudios en Biotecnología, Facultad de Medicina Veterinaria y Zootecnia, Universidad Michoacana de San Nicolás de Hidalgo. Doctorado en Biotecnología de Plantas por el Centro de Investigación y Estudios Avanzados, y Licenciado Químico Bacteriólogo y Parasitólogo por la Escuela Nacional de Ciencias Biológicas, ambos del Instituto Politécnico Nacional. Formó parte de la mesa directiva de la Asociación Mexicana de Microbiología (2017-2019) Los proyectos de investigación que desarrolla son en epidemiología molecular de enfermedades infecciosas, en el aislamiento y estudio de bacteriófagos y sus endolisinas para el control de enfermedades infecciosas y en el estudio de la regulación de la expresión genética de bacterias patógenas en el contexto de la endocrinología microbiana. Ha sido integrante del Sistema Nacional de Investigadores Nivel । (2003-2019) y actualmente cuenta con el nombramiento de Perfil deseable del PRODEp. Integrante del Cuerpo Académico Consolidado Microbiología Celular y Genética Molecular UMSNH-CA-188.

\section{Introducción}

Al escuchar la palabra "virus" reaccionamos con temor debido a las experiencias recientes por la pandemia causada por el coronavirus SARS-CoV-2. El significado de la palabra virus proviene del latín que significa veneno o ponzoña. Los virus infectan a los animales, plantas, hongosy a las bacterias. Los bacteriófagos, también llamados fagos, son un tipo de virus, y son partículas formadas por moléculas de ácido desoxirribonucleico (ADN) o ácido ribonucleico (ARN) y proteínas. Ellos infectan exclusivamente a las bacterias y son sus enemigos naturales. Los virus bacteriófagos son parásitos, que secuestran y utilizan los componentes de la célula para reproducirse (Salmond y Fineran, 2015).

\section{Un descubrimiento "viral"}

Los bacteriófagos fueron descubiertos, antes que los antibióticos, de manera independiente por Frederick Twort en 1915 y Félix d'Hérelle en 1917 (Salmond y Fineran, 2015). Su descubrimiento se considera uno de los más importantes en la historia moderna de la investigación biomédica, ya que fueron considerados como una herramienta muy prometedora contra las infecciones bacterianas. Félix d'Hérelle, en 1919, en París, fue el primer científico en administrar bacteriófagos por vía oral a niños con diarrea ocasionada por una infección con la bacteria Shigella dysenteriae. Los niños se recuperaron en 24 horas (Sulakvelidze y Kutter, 2005). No obstante, con el descubrimiento de la penicilina, el primer antibiótico, por Sir Alexander Fleming en 1928, los bacteriófagos quedaron relegados a un segundo plano. 


\section{Conociendo al enemigo íntimo de las bacterias}

Figura 1. Familias de bacteriófagos y sus representantes. A. Clasificación de bacteriófagos de acuerdo con la forma de su cápsula y al tipo de ácido nucléico (ADN O ARN). B. Bacteriófago próximo a unirse a la superficie de una célula. C. Módulo lunar sobre la superficie de la luna. El "cuello" del bacteriófagos es un canal por el que el ADN O ARN se inyecta en la bacteria, semejante al túnel de salida del módulo lunar por donde desembarcan los astronautas.
Los bacteriófagos, como todos los virus, están compuestos por una cubierta protectora de proteína llamada cápside, que asemeja a una cápsula de alunizaje, como la que llevó al hombre a la luna (ver figura 1). Dentro contiene material genético, que puede ser ácido desoxirribonucléico (ADN) o ácido ribonucleico (ARN). Los bacteriófagos se clasifican con base en la forma de su cápside (si tienen cola, si la cápside presenta formas variadas, o si es filamentosa o poliédrica; ver figura 1).
A

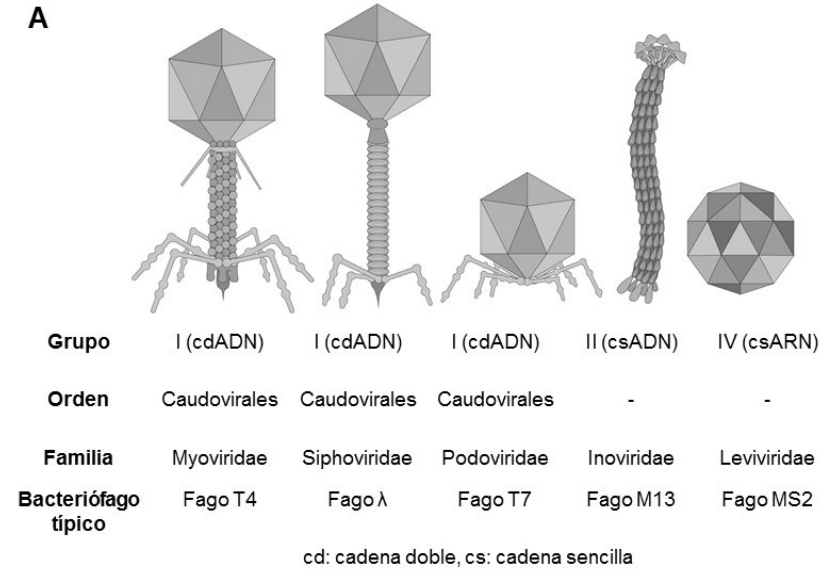

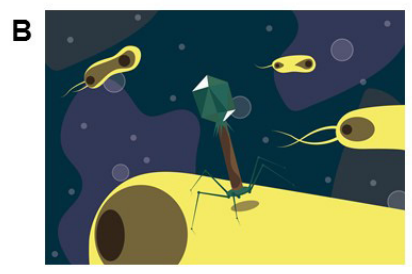

c

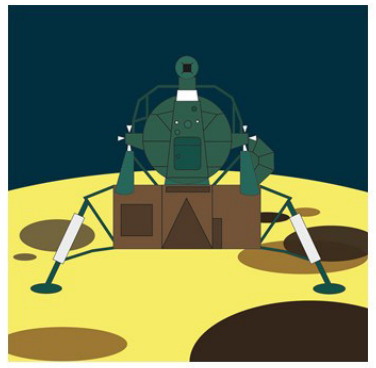

Los bacteriófagos miden entre 50 y 200 nm (1 nm = 1 mil millonésima parte de un metro) (Richter et al., 2018) y sólo pueden ser visibles con un microscopio electrónico. Son las entidades biológicas más abundantes en la Tierra, superando 10 veces el número de bacterias en algunos ecosistemas (Dion et al., 2020). Los bacteriófagos son abundantes en el medio acuático, suelo, plantas y en los animales. En los humanos, los fagos se pueden encontrar en la piel, la boca, el estómago y el intestino, donde se han encontrado hasta 100 millones de partículas virales por ml de filtrados fecales (Hoyles et al., 2014).

\section{¿Cómo infectan los bacteriófagos a las bacterias?}

Los bacteriófagos reconocen de manera muy específica a las bacterias que invadirán. Para ello, se adhieren a la superficie bacteriana e inyectan su material genético dentro de la célula. Si el material genético del fago se combina con el material genético de la bacteria anfitriona, se le llama profago; en este caso, ambos se pueden replicar simultáneamente y la bacteria no es destruida, lo que se conoce como el ciclo de vida lisogénico del fago (Melo et al., 2020). En el caso de los fagos líticos, en cambio, al inyectar su material genético, éste es leído e interpretado por la bacteria para producir más moléculas de ADN O ARN del fago, 
"El enemigo de mi enemigo es... Un virus que ataca a las bacterias: los bacteriófagos" María Anel Fuentes Valencia, Adriana Carolina Gil Correa, Carlos Antonio Martínez Palacios,

Víctor Manuel Baizabal Aguirre y Juan José Valdez Alarcón

Vol. 22, Núm. 4, julio-agosto 2021 Revista Digital Universitaria

proteínas de la cápside y una enzima llamada endolisina, que, en cuestión de minutos a horas, destruye a sus anfitriones, para liberar miles de bacteriófagos (ver figura 2). Este ciclo lítico se repite hasta que se agotan las bacterias por secuestrar. Los fagos líticos se consideran idóneos para el control de enfermedades de origen bacteriano (Melo et al., 2020).

Figura 2. Ciclos de vida de los bacteriófagos.

${ }^{1}$ Vector molecular. El material genético del bacteriófago es modificado y se utiliza para transportar y almacenar información genética de otros organismos.

2 Ingeniería genética: es el uso de las "tijeras moleculares", el "pegamento molecular" y otras enzimas para modificar la información genética de un organismo.

${ }^{3}$ La Biología Sintética es el uso de la ingeniería genética para el diseño de sistemas biológicos con propiedades nuevas que normalmente no se encuentran en la naturaleza.

${ }^{4}$ De siglas en inglés que significan repeticiones palindrómicas cortas agrupadas y regularmente interespaciadas asociadas a la nucleasa Cas9.

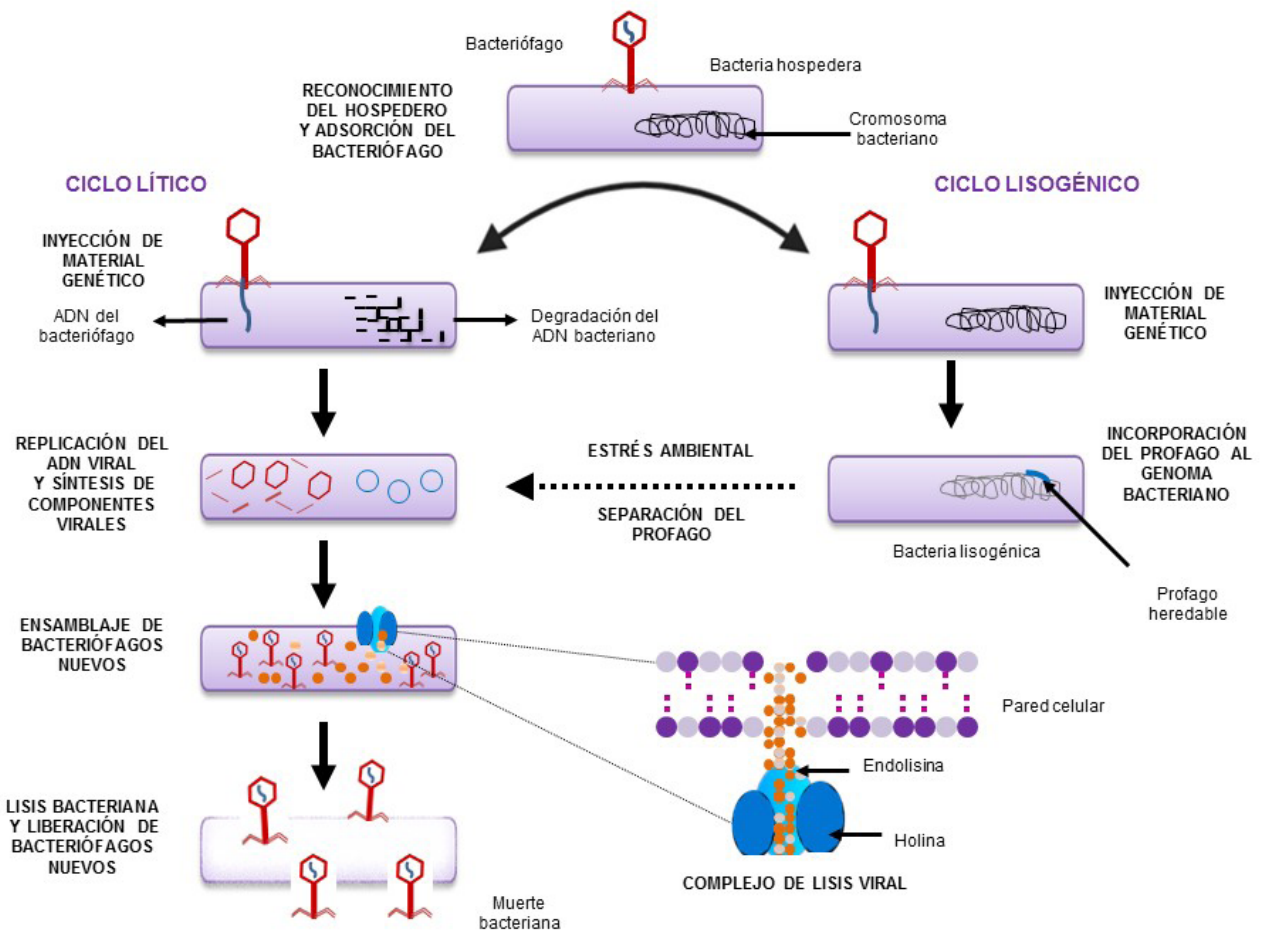

Los bacteriófagos y el avance de la biología molecular

El estudio de los bacteriófagos contribuyó al conocimiento de la biología molecular. Hershey y Chase, en 1952, al estudiar un bacteriófago, demostraron que los genes estaban hechos de ácidos nucleicos. De la interacción entre bacteria y bacteriófago se descubrieron varias enzimas. Entre ellas las enzimas de restricción, que las bacterias utilizan como "tijeras moleculares", para cortar el ADN del virus infectante; la ligasa, que actúa como "pegamento molecular". De igual manera, el material genético de un bacteriófago se ha usado como vector molecular.

Dichas herramientas tienen diferentes aplicaciones en la biología molecular, la ingeniería genética ${ }^{2}$ y la biotecnología. Por ejemplo, la aRn polimerasa y la ribonucleasa $\mathrm{H}$ de bacteriófagos de Escherichia coli se usan como herramientas en biología sintética ${ }^{3}$, y en un futuro podrían utilizarse para nanodispositivos y en la construcción de los genomas para células artificiales que realicen funciones útiles para la humanidad (Kim y Winfre, 2011). Asimismo, una de las herramientas de edición genética más recientes y versátiles, CRISPR-Cas ${ }^{4}$, deriva de un mecanismo de defensa bacteriano contra los bacteriófagos, y permite la ingeniería genética in vivo en bacterias y células más complejas, como las de mamíferos o plantas (Mei et al., 2016). 
"El enemigo de mi enemigo es... Un virus que ataca a las bacterias: los bacteriófagos" María Anel Fuentes Valencia, Adriana Carolina Gil Correa, Carlos Antonio Martínez Palacios, Víctor Manuel Baizabal Aguirre y Juan José Valdez Alarcón

Vol. 22, Núm. 4, julio-agosto 2021 Revista Digital Universitaria

\section{Terapias con bacteriófagos}

Un proverbio árabe dice: "el enemigo de mi enemigo es mi amigo". Por ello, como los bacteriófagos destruyen a las bacterias que nos atacan y enferman, entonces, son nuestros aliados. En este sentido, el interés en el uso de los bacteriófagos para el control de enfermedades es cada vez mayor, principalmente debido al incremento de las bacterias resistentes a varios tipos de antibióticos, las Ilamadas superbacterias, cada vez más difíciles de combatir. Las superbacterias son un problema de salud pública urgente, ya que cada vez hay menos antibióticos nuevos y efectivos. Los Centros para el Control y Prevención de Enfermedades estiman 2.8 millones de infecciones por superbacterias en los Estados Unidos, que cada año causan más de 35,000 muertes (Centers for Disease Control and Prevention [CDC], 2020). También la Organización Mundial de la Salud (oms) alerta de la importancia en el incremento de las superbacterias, por lo que actualmente establece políticas y estrategias de control bajo el enfoque integral de "Una Salud", que considera la salud humana, animal, vegetal y el ambiente (oms, 2020).

La terapia de bacteriófagos, que utiliza fagos para tratar las infecciones bacterianas, existe desde el siglo pasado y presenta numerosas ventajas en comparación con la terapia con antibióticos (Melo et al., 2020):

1) Los bacteriófagos son abundantes en la naturaleza y de bajo costo: un solo bacteriófago puede aniquilar a un número elevado de bacterias.

2) Los bacteriófagos líticos destruyen por completo a las bacterias, a diferencia de los antibióticos bacteriostáticos ${ }^{5}$, que dificultan la reproducción de las bacterias, pero no las eliminan.

3) Los bacteriófagos son muy específicos. Infectan únicamente a su bacteria hospedera, dejando intactas a otras bacterias benéficas. Además, no infectan a los humanos, animales o plantas.

4) Es una terapia activa ${ }^{6}$, una sola dosis es suficiente para el control de la infección bacteriana. Mientras existan bacterias, los bacteriófagos continuarán replicándose; una vez eliminadas, también dejarán de multiplicarse.

5) Los bacteriófagos pueden cambiar (mutar) para evadir las defensas de las bacterias. Es posible usar mezclas (cócteles) de bacteriófagos para evitar el desarrollo de resistencia bacteriana.

6) Los bacteriófagos no causan alergias como lo hacen algunos antibióticos.

\section{Bacteriófagos al rescate de la salud humana y animal}

${ }^{5}$ Bacteriostático: antibiótico que retrasa o impide el crecimiento de una bacteria, pero no las mata.

${ }^{6}$ Terapia activa, una vez administrada su efecto es duradero.
Durante 1950 en Europa, Áfricayen los Estados Unidos, se utilizaron preparaciones preventivas y terapéuticas de bacteriófagos que fueron desplazadas por los antibióticos en el mercado. Los bacteriófagos terapéuticos se administran en los humanos a través diversas rutas: por aerosol, intravenosa, oral, rectal y tópica, para el tratamiento de diversas infecciones bacterianas (Melo et al., 2020). 
"El enemigo de mi enemigo es... Un virus que ataca a las bacterias: los bacteriófagos" María Anel Fuentes Valencia, Adriana Carolina Gil Correa, Carlos Antonio Martínez Palacios, Víctor Manuel Baizabal Aguirre y Juan José Valdez Alarcón

Vol. 22, Núm. 4, julio-agosto 2021 Revista Digital Universitaria

Los bacteriófagos son muy seguros, dado que hemos estado expuestos a ellos desde que estuvimos en el útero y hemos desarrollado tolerancia a su presencia. Existen ensayos clínicos y casos de éxito de la fagoterapia, sobre todo en Europa (Sulakvelidze y Kutter, 2005). A pesar de su éxito, ningún bacteriófago cuenta con aprobación para su uso terapéutico en humanos, aunque algunos productos terapéuticos con base en bacteriófagos cuentan con autorización por la Unión Europea para aplicarse en las granjas avícolas. A la fecha sólo algunas formulaciones de bacteriófagos en la industria alimentaria humana se autorizan por la Agencia Federal de Medicamentos y Alimentos (FDA) de los Estados Unidos, quien los considera como "generalmente seguros".

Existen casos, científicamente documentados, de terapia con bacteriófagos exitosa en los humanos. Thomas Patterson, un paciente diabético con pancreatitis infecciosa por Acinetobacter baumannii con multirresistencia a los antibióticos, recibió una terapia personalizada, un cóctel de nueve bacteriófagos con potencial destructor, administrado en las cavidades de los abscesos. Después de dicho tratamiento el paciente recuperó su salud, sin presentar efectos negativos a causa de la terapia con bacteriófagos (Schooley et al., 2017). Otro caso es el de Isabelle Camell-Holdaway, una adolescente de 15 años con fibrosis quística, una enfermedad genética que afecta la función pulmonar. Al mes de someterse a un trasplante de pulmones presentó una infección en todo el cuerpo con llagas ocasionadas por Mycobacterium abscessus. A pesar de que los médicos estimaron una sobrevivencia nula, la administración de un cóctel de bacteriófagos mejoró notablemente la salud de la joven, incluso las heridas abiertas lograron cerrarse (Dedrick et al., 2019). Asimismo, los bacteriófagos rescatan la salud de animales terrestres y acuáticos. Algunos casos de éxito se observan en la tabla 1.

Tabla 1. Ejemplos de aplicaciones de los bacteriófagos en la salud humana y animal.

*Bajo la legislación Europea

\begin{tabular}{|c|c|c|c|c|c|}
\hline Uso & $\begin{array}{l}\text { Organismo/ } \\
\text { producto } \\
\text { alimenticio }\end{array}$ & Bacteriófago & Patógeno & $\begin{array}{l}\text { Aplicación } \\
\text { resultados }\end{array}$ & Cita \\
\hline $\begin{array}{l}\text { Medicina } \\
\text { veterinaria }\end{array}$ & Perros & $\begin{array}{l}\text { Cóctel de } 6 \\
\text { bacteriófagos }\end{array}$ & $\begin{array}{l}\text { Pseudomonas } \\
\text { aeruginosa }\end{array}$ & $\begin{array}{l}\text { Topica. } \\
\text { Redujo las } \\
\text { bacterias a las } \\
48 \text { h. } \\
\text { Primer informe } \\
\text { de terapia con } \\
\text { bacteriófagos.* }\end{array}$ & $\begin{array}{l}\text { Hawkins et } \\
\text { al., } 2010\end{array}$ \\
\hline $\begin{array}{l}\text { Medicina } \\
\text { veterinaria }\end{array}$ & $\begin{array}{l}\text { Truchas arco } \\
\text { iris }\end{array}$ & PAS-1 & $\begin{array}{l}\text { Aeromonas } \\
\text { salmonicida }\end{array}$ & $\begin{array}{l}\text { Inyección } \\
\text { intramuscular. } \\
\text { Incrementó la } \\
\text { superviviencia de } \\
\text { los peces. } \\
\text { Ausencia de } \\
\text { lesiones externas. }\end{array}$ & $\begin{array}{l}\text { Kim et al., } \\
2013\end{array}$ \\
\hline $\begin{array}{l}\text { Diagnóstico } \\
\text { clínico }\end{array}$ & Humano & $\begin{array}{l}\varphi A 1122 \text { y } \\
L-413 C\end{array}$ & Yersinia pestis & $\begin{array}{l}\text { La detección } \\
\text { molecular de los } \\
\text { bacteriófagos } \\
\text { permitió una } \\
\text { identificación } \\
\text { bacteriana rápida. }\end{array}$ & $\begin{array}{l}\text { Sergueev et } \\
\text { al., } 2015\end{array}$ \\
\hline
\end{tabular}


"El enemigo de mi enemigo es... Un virus que ataca a las bacterias: Ios bacteriófagos" María Anel Fuentes Valencia, Adriana Carolina Gil Correa, Carlos Antonio Martínez Palacios, Víctor Manuel Baizabal Aguirre y Juan José Valdez Alarcón

Vol. 22, Núm. 4, julio-agosto 2021 Revista Digital Universitaria

\begin{tabular}{|l|l|l|l|l|l|}
\hline $\begin{array}{l}\text { Inocuidad } \\
\text { alimentaria }\end{array}$ & $\begin{array}{l}\text { Carne cruda } \\
\text { y cocinada }\end{array}$ & $\begin{array}{l}\text { Cóctel de 3 } \\
\text { bacteriófagos } \\
\text { para cada } \\
\text { bacteria }\end{array}$ & $\begin{array}{l}\text { Listeria } \\
\text { monocytogenes } \\
\text { y Escherichia } \\
\text { coli O157:H7 }\end{array}$ & $\begin{array}{l}\text { Bioadsorbentes } \\
\text { en membranas de } \\
\text { celulosa en carne } \\
\text { contaminada } \\
\text { Biocontrol } \\
\text { eficiente } \\
\text { bacteriano }\end{array}$ & $\begin{array}{l}\text { Anany et al., } \\
2011\end{array}$ \\
& & & & \\
\hline
\end{tabular}

\section{Las armas virales: las endolisinas y sus aplicaciones}

Los bacteriófagos producen holinas (proteínas formadoras de poro), que permiten la salida de las endolisinas, enzimas que degradan la pared celular bacteriana (Gondil et al., 2020; ver figura 2). Las endolisinas se consideran enzibióticos (enzimas con actividad antibiótica) con potencial para el tratamiento de infecciones bacterianas multirresistentes. Ya que son de naturaleza proteica, las endolisinas se consideran aún más seguras que los bacteriófagos al estar libres de material genético (Gondil et al., 2020). Hasta el momento no se ha identificado desarrollo de resistencia bacteriana a ellas, debido a que las moléculas que degradan poseen estructuras que prácticamente no cambian. Las endolisinas tienen un espectro de acción más amplio que los bacteriófagos, lo cual las hace más atractivas como fármacos. Existen investigaciones sobre la actividad antimicrobiana de las endolisinas con diversas aplicaciones (ver tabla 2), pero aún no existen fármacos comerciales basados en endolisinas.

\begin{tabular}{|c|c|c|c|c|c|}
\hline Uso & $\begin{array}{l}\text { Organismo } \\
\text { / producto } \\
\text { alimenticio }\end{array}$ & Endolisina & Patógeno & $\begin{array}{c}\text { Aplicación y } \\
\text { resultados }\end{array}$ & Cita \\
\hline $\begin{array}{l}\text { Medicina } \\
\text { humana y } \\
\text { veterinaria }\end{array}$ & $\begin{array}{l}\text { Células } \\
\text { pulmonares } \\
\text { humanas y } \\
\text { ratones }\end{array}$ & $\begin{array}{l}\text { LysSS } \\
\text { (endolisina } \\
\text { de } \\
\text { bacteriófago } \\
\text { vs } \\
\text { Salmonella } \\
\text { enterica) }\end{array}$ & $\begin{array}{l}\text { Acinetobacter } \\
\text { baumannii, P. } \\
\text { aeruginosa, } \\
\text { Staphylococcus } \\
\text { aureus, } \\
\text { enterobacterias }\end{array}$ & $\begin{array}{l}\text { In vitro resultó ser un } \\
\text { biocontrol efectivo } \\
\text { para bacterias } \\
\text { Gram- y Gram+. } \\
\text { Ausencia de efectos } \\
\text { citotóxicos en las } \\
\text { células humanas } \\
\text { Inyección } \\
\text { intraperitoneal } \\
\text { protegió a ratones } \\
\text { con infección por } A \text {. } \\
\text { baumanii }\end{array}$ & $\begin{array}{l}\text { Kim et al., } \\
2020\end{array}$ \\
\hline Agricultura & $\begin{array}{l}\text { Planta de } \\
\text { papa }\end{array}$ & $\begin{array}{l}\text { Lisozima del } \\
\text { Bacteriófago } \\
\text { T4 }\end{array}$ & $\begin{array}{l}\text { Erwinia } \\
\text { carotovora }\end{array}$ & $\begin{array}{l}\text { Tecnología genética } \\
\text { Las plantas con el } \\
\text { gen de la lisozima } \\
\text { fueron resistentes } \\
\text { a la infección } \\
\text { bacteriana. }\end{array}$ & $\begin{array}{l}\text { Düring et } \\
\text { al., } 1993\end{array}$ \\
\hline $\begin{array}{l}\text { Medicina } \\
\text { veterinaria }\end{array}$ & Mamíferos & SAL200 & S. aureus & $\begin{array}{l}\text { Inyección } \\
\text { intravenosa en } \\
\text { distintos modelos } \\
\text { animales. Reducción } \\
\text { de las bacterias en la } \\
\text { sangre. Incrementó } \\
\text { significativamente la } \\
\text { sobrevivencia de los } \\
\text { animales. }\end{array}$ & $\begin{array}{l}\text { Jun et al., } \\
\text { 2013; } \\
2016\end{array}$ \\
\hline
\end{tabular}


"El enemigo de mi enemigo es... Un virus que ataca a las bacterias: los bacteriófagos" María Anel Fuentes Valencia, Adriana Carolina Gil Correa, Carlos Antonio Martínez Palacios, Víctor Manuel Baizabal Aguirre y Juan José Valdez Alarcón

Vol. 22, Núm. 4, julio-agosto 2021 Revista Digital Universitaria

\begin{tabular}{|l|l|l|l|l|l|}
\hline $\begin{array}{l}\text { Inocuidad } \\
\text { alimentaria }\end{array}$ & $\begin{array}{l}\text { Leche de } \\
\text { soya }\end{array}$ & Lysz5 & $\begin{array}{l}\text { Listeria } \\
\text { monocytogenes en leche }\end{array}$ & $\begin{array}{l}\text { Directa } \\
\text { contaminada. } \\
\text { Reducción de la } \\
\text { bacteria }\left(3 \text { h, } 4^{\circ} \mathrm{C}\right)\end{array}$ & $\begin{array}{l}\text { Zhang et } \\
\text { al., } 2012\end{array}$ \\
\hline
\end{tabular}

Las endolisinas son útiles para el control de las biopelículas (acumulaciones de bacterias que secretan moléculas que las protegen y que dificultan la efectividad de los antibióticos; Love et al., 2018). Las endolisinas también se emplean para la desinfección de equipo hospitalario, y la elaboración y empaque de alimentos (Barrera et al., 2015). Dichas proteínas tienen un potencial importante en la industria alimentaria como aditivos antimicrobianos o de ser producidas por bacterias ácido lácticas modificadas, en procesos de fermentación. La endolisinas también tienen potencial de aplicación para el control de infecciones bacterianas en diversos sectores productivos, tal como el agropecuario y el acuícola (Zduńczyk y Janowski, 2020; Zermeño et al., 2018).

\section{Los bacteriófagos también son útiles de otras maneras}

Utilizando solamente las proteínas de la cápside del bacteriófago se construyen las partículas tipo virus (vLPS, por sus siglas del inglés Viral Like Particles), las cuales sirven para el diseño de vacunas contra infecciones virales. Las vLPS carecen de material genético para producir una infección, por lo que se consideran una estrategia segura para la inducción de anticuerpos neutralizantes, por ejemplo, contra la influenza. En esta vacuna, modificaron un bacteriófago filamentoso de E. coli y le insertaron una proteína del virus de influenza. El bacteriófago generó respuesta inmunológica protectora, en modelos animales, contra una dosis letal del virus de la influenza (Deng et al., 2015). De una manera similar, las VLPS derivadas de los bacteriófagos de cola se emplean para la generación de vacunas para enfermedades no infecciosas (cánceres de mama, pulmón, hígado, próstata y de piel).

Las endolisinas se utilizan para generar los llamados fantasmas bacterianos (Bacterial Ghosts o BGS, en inglés), células bacterianas que perdieron su contenido celular, quedando solamente la envoltura celular. La endolisina E del bacteriófago PhiX174 ocasiona la lisis celular de la bacteria en la que se produce, y una nucleasa procedente de Staphylococcus aureus (SNUC) degrada el ADN para garantizar que los BGS están libres de ácidos nucleicos. Los BGS se utilizan como sustitutos de las vacunas atenuadas por calor o inactivadas por tratamientos químicos; a diferencia de éstos, conservan la estructura tridimensional de sus proteínas lo que mejora su eficiencia como vacunas (Barrera et al., 2015). Con los BGS se han inmunizado a distintos modelos animales contra las bacterias: Vibrio cholerae, Klebsiella pneumoniae y Salmonella enterica. Los BGS se pueden emplear como micro-biorreactores para realizar reacciones enzimáticas, como transportadores de plaguicidas contra patógenos de plantas y en la entrega de medicamentos en la terapia antitumoral. Lo anterior permite una mayor especificidad hacia las células tumorales y una reducción en la cantidad de medicamento por aplicación (Hajam et al., 2017). Los bacteriófagos también 
"El enemigo de mi enemigo es... Un virus que ataca a las bacterias: los bacteriófagos" María Anel Fuentes Valencia, Adriana Carolina Gil Correa, Carlos Antonio Martínez Palacios, Víctor Manuel Baizabal Aguirre y Juan José Valdez Alarcón

Vol. 22, Núm. 4, julio-agosto 2021 Revista Digital Universitaria

se utilizan para el envío de genes reporteros a las bacterias y así generar un sistema para la detección de bacterias como E. coli, Listeria monocytogenes, S. Typhimurium, Yersinia pestis y Bacillus anthracis (Bardy et al., 2016).

Así, los bacteriófagos y las endolisinas son útiles para la detección rápida de las bacterias (Bai et al., 2016), y, por su especificidad para unirse a ellas, se pueden utilizar como biosondas, que presentan ventajas en comparación con los anticuerpos: replicación en gran número a un bajo costo y estabilidad ante condiciones desfavorables -variaciones en el pH, temperatura y salinidad (Bardy et al., 2016)-. Para la detección bacteriana, se utilizan también los dominios de unión de la pared celular bacteriana (CBD) de las endolisinas, debido a su unión específica con el huésped. Los CBD podrían ser candidatos potenciales para reemplazar los anticuerpos en la detección rápida y la determinación de la concentración de patógenos, ya que presentan una especificidad mayor y son más económicos (Bai et al., 2016).

\section{Conclusiones}

En nuestra historia, en un planeta lleno de virus, dentro de los cuales los bacteriófagos predominan y nos continuarán sorprendiendo, su estudio ha representado grandes avances para el desarrollo científico, particularmente para la biotecnología molecular y la biomedicina. La investigación de los bacteriófagos líticos nos permitirá emplearlos como nuestros aliados ante la guerra microbiana y en la mejora de los sectores productivos. En esta época post-antibiótica, el futuro de la terapia con bacteriófagos y sus endolisinas parece ser prometedor y versátil. No obstante, aún se requiere de investigación clínica que consolide finalmente la terapia con bacteriófagos. Además, éstos se consideran una tecnología verde, amigable con el medio ambiente y presentan otras cualidades que aún nos queda por explotar para el rescate de la salud humana, animal y vegetal.

\section{Agradecimientos}

El trabajo de bacteriófagos recibe apoyo del proyecto SENASICA "Desarrollo de una estrategia alternativa al uso de antibióticos para el biocontrol de cepas prevalentes de Aeromonas spp. en granjas trutícolas de Michoacán", del Laboratorio Nacional de Nutrigenómica y Microbiómica Digestiva Animal y de la Coordinación de la Investigación Científica de la Universidad Michoacana de San Nicolás de Hidalgo. Los autores agradecen a la Lic. en Diseño Gráfico Andrea Valdez Chávez por su colaboración en la elaboración de la Figura 1.

\section{Referencias}

* Anany, H., Chen, W., Pelton, R. y Griffiths, M. W. (2011). Biocontrol of Listeria monocytogenes and Escherichia coli O157: $\mathrm{H} 7$ in meat by using phages immobilized on modified cellulose membranes. Applied and environmental microbiology, 77(18), 6379-6387. https://doi.org/10.1128/AEM.05493-11 
"El enemigo de mi enemigo es... Un virus que ataca a las bacterias: los bacteriófagos" María Anel Fuentes Valencia, Adriana Carolina Gil Correa, Carlos Antonio Martínez Palacios, Víctor Manuel Baizabal Aguirre y Juan José Valdez Alarcón

Vol. 22, Núm. 4, julio-agosto 2021 Revista Digital Universitaria

* Bai, J., Kim, Y. T., Ryu, S. y Lee, J. H. (2016). Biocontrol and rapid detection of foodborne pathogens using bacteriophages and endolysins. Frontiers in microbiology, 7, 474. https://doi.org/10.3389/fmicb.2016.00474

* Bárdy, P., Pantůček, R., Benešík, M. y Doškař, J. (2016). Genetically modified bacteriophages in applied microbiology. Journal of Applied Microbiology, 121(3), 618-33. https://doi.org/10.1111/jam.13207

* Barrera, R. C.I., Cajero, J.M., Oviedo, B. J., Nuñez A. R. E., Kawabe, K. L. y Alarcón, V. J. J. (2015). Advances in the use of endolysins: general remarks, structure, applications, genetic modifications and perspectives. En A. Mendez-Vilas (Ed), The Battle Against Microbial Pathogens: Basic Science, Technological Advances and Educational Programs (pp. 259-268). Formatex Research Center.

* Centers for Disease Control and Prevention (CDC). (2020, 13 de marzo). Antibiotic / Antimicrobial Resistance (AR/AMr). About Antibiotic Resistance. https://www.cdc.gov/ drugresistance/about.html

* Chauthaiwale, V. M., Therwath, A. y Deshpande, V. V. (1992). Bacteriophage lambda as a cloning vector. Microbiology and Molecular Biology Reviews, 56(4), 577-591.

Dedrick, R. M., Guerrero,B. C. A., Garlena, R. A., Russell, D. A., Ford, K., Harris, K., Gilmour K. C., Soothill J., Jacobs S. D., Schooley R. T., Hatfull, G. F. y Spencer, H. (2019). Engineered bacteriophages for treatment of a patient with a disseminated drug-resistant Mycobacterium abscessus. Nature medicine, 25(5), 730-733. https:// doi.org/10.1038/s41591-019-0437-z

* Deng, L., Ibañez, L. I., Van den Bossche, V., Roose, K., Youssef, S. A., De Bruin, A., Fiers W. y Saelens, X. (2015). Protection against influenza A virus challenge with M2e-displaying filamentous Escherichia coli phages. PLoS One, 10(5), e0126650. https://doi.org/10.1371/journal.pone.0126650

- Dion, M. B., Oechslin, F. y Moineau, S. (2020). Phage diversity, genomics and phylogeny. Nature Reviews Microbiology, 18, 125-138. https://doi.org/10.1038/ s41579-019-0311-5

* Düring, K., Porsch, P., Fladung, M. y Lörz, H. (1993). Transgenic potato plants resistant to the phytopathogenic bacterium Erwinia carotovora. The Plant Journal, 3(4), 587-598. https://doi.org/10.1046/j.1365-313X.1993.03040587.x

* Gondil, V. S., Harjai, K. y Chhibber, S. (2020). Endolysins as emerging alternative therapeutic agents to counter drug-resistant infections. International journal of antimicrobial agents, 55(2), 105844. https://doi.org/10.1016/j. ijantimicag.2019.11.001

* Hajam, I. A., Dar, P. A., Won, G. y Lee, J. H. (2017). Bacterial ghosts as adjuvants: mechanisms and potential. Veterinary Research, 48, 37. https://doi.org/10.1186/ s13567-017-0442-5

* Hawkins, C., Harper, D., Burch, D., Änggård, E. y Soothill, J. (2010). Topical treatment of Pseudomonas aeruginosa otitis of dogs with a bacteriophage mixture: a before/after clinical trial. Veterinary microbiology, 146(3-4), 309-313. https://doi. org/10.1016/j.vetmic.2010.05.014 
"El enemigo de mi enemigo es... Un virus que ataca a las bacterias: los bacteriófagos" María Anel Fuentes Valencia, Adriana Carolina Gil Correa, Carlos Antonio Martínez Palacios, Víctor Manuel Baizabal Aguirre y Juan José Valdez Alarcón

Vol. 22, Núm. 4, julio-agosto 2021 Revista Digital Universitaria

* Hoyles, L., McCartney, A. L., Neve, H., Gibson, G. R., Sanderson, J. D., Heller, K. J. y Van Sinderen, D. (2014). Characterization of virus-like particles associated with the human faecal and caecal microbiota. Research in microbiology, 165(10), 803812. https://doi.org/10.1016/j.resmic.2014.10.006

Jackson, D. A., Symons, R. H. y Berg, P. (1972). Biochemical method for inserting new genetic information into DNA of Simian Virus 40: circular SV40 DNA molecules containing lambda phage genes and the galactose operon of Escherichia coli. Proceedings of the National Academy of Sciences, 69(10), 2904-2909. https://doi. org/10.1073/pnas.69.10.2904

* Jun, S. Y., Jung, G. M., Yoon, S. J., Oh, M. D., Choi, Y. J., Lee, W. J. y Kang, S. H. (2013). Antibacterial properties of a pre-formulated recombinant phage endolysin, SAL-1. International journal of antimicrobial agents, 41(2), 156-161. https://doi.org/10.1016/j. ijantimicag.2012.10.011

Jun, S. Y., Jung, G. M., Yoon, S. J., Youm, S. Y., Han, H. Y., Lee, J. H. y Kang, S. H. (2016). Pharmacokinetics of the phage endolysin-based candidate drug SAL 200 in monkeys and its appropriate intravenous dosing period. Clinical and Experimental Pharmacology and Physiology, 43(10), 1013-1016. https://doi.org/10.1111/14401681.12613

Kim, J. H., Choresca, C. H., Shin, S. P., Han, J. E., Jun, J. W. y Park, S. C. (2013). Biological Control of Aeromonas salmonicida subsp. salmonicida Infection in Rainbow Trout (Oncorhynchus mykiss) Using Aeromonas Phage PAs-1. Transboundary and emerging diseases, 62(1), 81-86. https://doi.org/10.1111/tbed.12088

* Kim, J. y Winfree, E. (2011). Synthetic in vitro transcriptional oscillators. Molecular systems biology, 7, 465. https://doi.org/10.1038/msb.2010.119

- Kim, S., Lee, D. W., Jin, J. S. y Kim, J. (2020). Antimicrobial activity of LysSS, a novel phage endolysin, against Acinetobacter baumannii and Pseudomonas aeruginosa. Journal of Global Antimicrobial Resistance, 22, 32-39. https://doi.org/10.1016/j. jgar.2020.01.005

* Love, M. J., Bhandari, D., Dobson, R. C. y Billington, C. (2018). Potential for bacteriophage endolysins to supplement or replace antibiotics in food production and clinical care. Antibiotics, 7(1), 17. https://doi.org/10.3390/antibiotics7010017

* Mei, Y., Wang, Y., Chen, H., Sun, Z. S. y Ju, X. D. (2016). Recent progress in CRISPR/ Cas9 technology. Journal of Genetics and Genomics, 43(2), 63-75. https://doi. org/10.1016/j.jgg.2016.01.001

* Melo, L. D., Oliveira, H., Pires, D. P., Dabrowska, K. y Azeredo, J. (2020). Phage therapy efficacy: a review of the last 10 years of preclinical studies. Critical Reviews in Microbiology, 46(1), 78-99. https://doi.org/10.1080/1040841X.2020.1729695

* Organización Mundial de la Salud (oms). (2020, septiembre). El enfoque multisectorial de la oms "Una salud". https://www.who.int/features/qa/one-health/ es/

* Richter, L., Janczuk R., M., Niedziółka J.J., Paczesny J., Hołyst, R. (2018). Recent advances in bacteriophage-based methods for bacteria detection. Drug Discovery Today, 23(2), 448-455. https://doi.org/10.1016/j.drudis.2017.11.007 
"El enemigo de mi enemigo es... Un virus que ataca a las bacterias: los bacteriófagos" María Anel Fuentes Valencia, Adriana Carolina Gil Correa, Carlos Antonio Martínez Palacios, Víctor Manuel Baizabal Aguirre y Juan José Valdez Alarcón

Vol. 22, Núm. 4, julio-agosto 2021 Revista Digital Universitaria

* Salmond, G. P. y Fineran, P. C. (2015). A century of the phage: past, present and future. Nature Reviews Microbiology, 13(12), 777-786. https://doi.org/10.1038/ nrmicro3564

* Sergueev, K. V., He, Y., Borschel, R. H., Nikolich, M. P. y Filippov, A. A. (2010). Rapid and sensitive detection of Yersinia pestis using amplification of plague diagnostic bacteriophages monitored by real-time PCR. PLoS One, 5(6), e11337. https://doi. org/10.1371/journal.pone.0011337

* Schooley, R. T., Biswas, B., Gill, J. J., Hernández M. A., Lancaster, J., Lessor, L. y Segall, A. M. (2017). Development and use of personalized bacteriophage-based therapeutic cocktails to treat a patient with a disseminated resistant Acinetobacter baumannii infection. Antimicrobial agents and chemotherapy, 61(10), e00954-17. https://doi.org/10.1128/AAC.00954-17

Sulakvelidze, A. y Kutter, E. (2004). Bacteriophage Therapy in Humans. En E. Kutter y A. Sulakvelidze (Eds.), Bacteriophages: biology and applications. cRc-Press. https:// doi.org/10.1201/9780203491751.ch14

* Zermeño-Cervantes, L. A., Makarov, R., Lomelí-Ortega, C. O., Martínez-Díaz, S. F. y Cardona-Félix, C. S. (2018). Recombinant Lys vPMS 1 as an endolysin with broad lytic activity against Vibrio parahaemolyticus strains associated to acute hepatopancreatic necrosis disease. Aquaculture Research, 49(4), 1723-1726. https://doi.org/10.1111/are.13577

* Zduńczyk, S. y Janowski, T. (2020). Bacteriophages and associated endolysins in therapy and prevention of mastitis and metritis in cows: Current knowledge. Animal Reproduction Science, 218, 106504. https://doi.org/10.1016/j. anireprosci.2020.106504

* Zhang, H., Bao, H., Billington, C., Hudson, J. A. y Wang, R. (2012). Isolation and lytic activity of the Listeria bacteriophage endolysin LysZ5 against Listeria monocytogenes in soya milk. Food microbiology, 31(1), 133-136. https://doi. org/10.1016/j.fm.2012.01.005

\section{Cómo CITAR ESTE ARTículo}

* Fuentes Valencia, María Anel, Gil Correa, Adriana Carolina, Martínez Palacios, Carlos Antonio, Baizabal Aguirre, Víctor Manuel y Valdez Alarcón, Juan José. (2021, julio-agosto). El enemigo de mi enemigo es... Un virus que ataca a las bacterias: los bacteriófagos. Revista Digital Universitaria ( ), 22(4). http://doi.org/10.22201/ cuaieed.16076079e.2021.22.4.1 